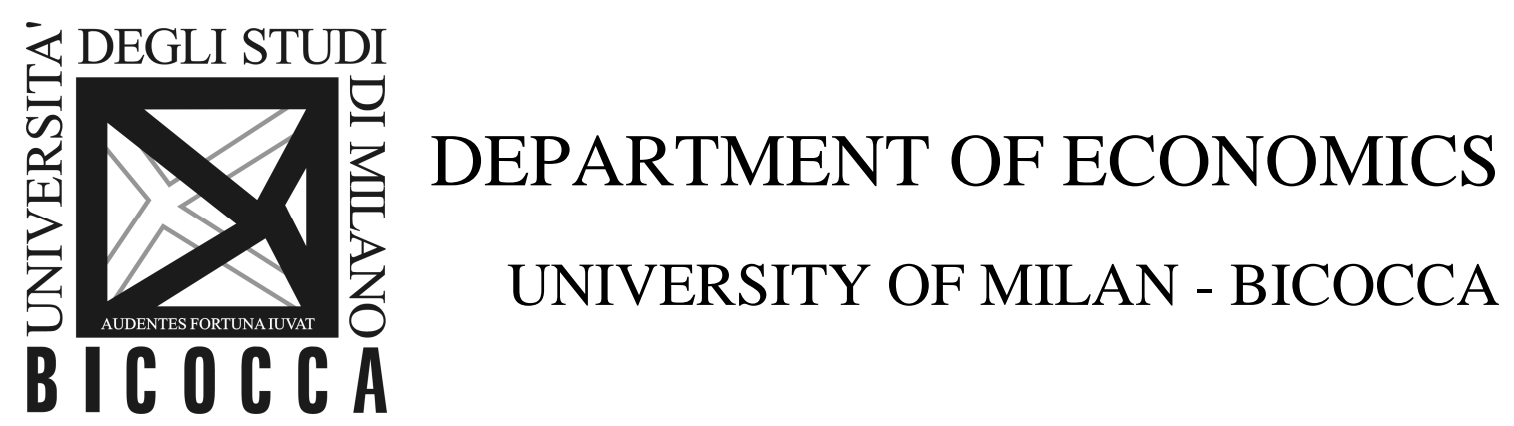

WORKING PAPER SERIES

\title{
Political Geography and Income Inequalities
}

Filippo Gregorini

No. 152 - February 2009

Dipartimento di Economia Politica

Università degli Studi di Milano - Bicocca

http://dipeco.economia.unimib.it 


\title{
Political Geography and Income Inequalities
}

\author{
Filippo Gregorini* \\ Dipartimento di Economia Politica \\ Università degli Studi di Milano - Bicocca \\ filippo.gregorini@unimib.it
}

February 2009

\begin{abstract}
This paper displays an analysis of geopolitical organizations within the framework proposed by Alesina and Spolaore (1997), where heterogeneity concerns the geographical space. This model adds heterogeneity in terms of income. Main results of the paper: (i) in the normative equilibrium (social planner solution) there is an inverse relationship between income inequality and public good provision within each jurisdiction; (ii) in the positive equilibrium (equilibrium geography) we find that in some cases there are no equilibria depending upon income inequality.

Key Words: Jurisdiction Size, Public Spending, Income Distribution, Tax Distortion.
\end{abstract}

JEL Code: D3, D6, H2, H4.

${ }^{*}$ This article is based on the first chapter of my Ph.D. thesis at the Graduate School of the Economics and Finance of Public Administration (DEFAP) in Milan. I am grateful to Mario Gilli, Francesco de Sinopoli, Federico Etro, Shlomo Weber, Claudio Zoli, Sandro Brusco, Michel Le Breton and Giovanna Iannantuoni. I'd like to thank also seminar participants at DEFAP Milan-Cattolica, DSE Verona, CORE Louvain-la-Neuve, ECINEQ Berlin, DEP Milan-Bicocca, Collegio Carlo Alberto Turin and GRASS Bologna for their useful comments. All errors are mine. 


\section{Introduction}

This paper studies a model of geopolitical organization where the size of nations and the level of public good provision are endogenous variables. Population is described by a double heterogeneity: individuals are located on a segment representing the world and there are different income levels. The introduction of income heterogeneity is the original contribution of our paper, whose benchmark models are Alesina and Spolaore (1997) and Etro (2006). Our purpose is to check the robustness of their results after the introduction of income inequalities as suggested in 1997 by Alesina and Spolaore: "differences in income...may be crucial determinants... of the equilibrium size and number of countries". ${ }^{1}$

More generally, this paper is intended to discuss the effects of income inequality on public spending and political instability from a theoretical point of view.

Political geography have been already explored under many perspectives: the first works are Friedman (1977) and Buchanan and Faith (1987) on country formation and secessions. They can be considered pioneers of this discipline, whose diffusion increased together with the number of nations in the nineties, when country borders have been redrawn to an extent that is absolutely exceptional for a peacetime period.

In the model by Alesina and Spolaore (1997) the size of nations is endogenously determined through the trade-off between scale economies and heterogeneity; in their work population is uniformly distributed, geographical and preference dimensions coincide and public spending is exogenous and independent from size. In Etro (2006) public spending is endogenous and it depends upon size through a budget constraint. Etro considers also the elasticity of marginal utility from public good as a variable of his model.

Our analysis focuses on the effects of the introduction of income heterogeneity in the model of Alesina and Spolaore modified $\grave{a}$ la Etro; we will show how income inequality affects size and public good provision.

The effects of income heterogeneity have been already explored in similar contexts by Bolton and Roland (1997) and Haimanko, Le Breton and Weber (2005). Bolton and Roland analyzed how income differences between regions can influence the break-up or unification of countries. They are not interested in the determination of the size of nations; their model emphasizes political conflicts over redistribution policies in jurisdictions where the decision to separate or to unify is taken by majority voting. A trade-off between

\footnotetext{
${ }^{1}$ Quarterly Journal of Economics, vol.CXII, page 1046.
} 
efficiency gains of unification and costs in terms of loss of control on political decisions is highlighted. Haimanko, Le Breton and Weber focused on threats of secession in a model where population is not uniformly distributed. They underline how efficiency implies stability only if the differences in citizens' preferences due to the geographical distribution of population are sufficiently small. If such differences are great enough efficient countries are not stable and redistribution schemes are needed in order to prevent secessions. Notice that both Bolton and Roland (1997) and Haimanko, Le Breton and Weber (2005) focus on threats of secession within a single country.

Our model considers a plurality of countries. Heterogeneity is given by individuals' location and income distribution. Furthermore, population is continuously and uniformly distributed and individuals are not mobile in contrast with the literature that follows Tiebout (1956). The issue of multidimensional heterogeneity in a context with a large number of jurisdictions has been already analyzed within the framework of Tiebout by Perroni and Scharf (2001).

Our analysis focuses on normative equilibrium ${ }^{2}$ through a two stage process: in the first stage, an utilitarian social planner chooses the size of jurisdictions and the amount of public good within each jurisdiction; ${ }^{3}$ in the second stage, the social planner chooses the location of public good in order to minimize the "costs of distance" from it within each jurisdiction. We find that there is an inverse relationship between public good provision and income inequality.

We also check the existence of stable equilibria under rules for border redrawing; that is, the positive equilibria ${ }^{4}$ of our model: we show that there are cases where positive equilibria do not exist depending upon the distribution of incomes.

This paper is organized as follows: Section 2 presents the model; Section 3 derives the normative equilibrium (social planner solution); Section 4 defines and characterizes the positive equilibrium (equilibrium geography); Section 5 concludes. At the end of the paper, there is a short Appendix.

\footnotetext{
${ }^{2}$ In this paper, the social planner solution can be considered as a "constrained optimum" or "second best solution", given that we assume the presence of a distortionary taxation scheme.

${ }^{3}$ Beyond different assumptions on individuals' mobility, the model by Perroni and Scharf does not consider the social planner solution and focus on a locational model of local fiscal choices where jurisdictions consist of open-membership coalitions of individuals and the levels of local public good provision are selected by majority voting.

${ }^{4}$ In this paper, we refer to positive equilibrium following the notions of stability discussed in Alesina and Spolaore (1997) and Etro (2006). Details are in Section 4.
} 


\section{The model}

\subsection{General assumptions}

World population has mass equal to 1 ; individuals are continuously and uniformly distributed on the segment $[0,1]$ and they are not mobile.

Individuals are divided in two groups, call them "poor" and "rich". There is no income heterogeneity within groups: $y_{P}=y$ is the income of poor individuals and $y_{R}=k y$ is the income of rich individuals, where $k>1$ measures income differential between groups.

The parameter $\alpha$ represents the share of poor individuals and $1-\alpha$ is the share of rich individuals. We assume that $\alpha$ is greater than 0.5 in order to guarantee the skewness to the right of income distribution as it is empirically observed.

In every point of the segment $[0,1]$ there are $\alpha$ poor individuals and $1-\alpha$ rich individuals.

Income of poor individuals: $y_{P}=y$

Income of rich individuals: $y_{R}=k y$

Average income: $\bar{y}=\alpha y+(1-\alpha) k y$

$\Longrightarrow$

$y_{R}>\bar{y}>y_{P}$

\subsection{Utility of individual $i$}

Utility of individual $i$ in country $j$ depends upon public spending and private consumption:

$$
U_{i j}=f(i) H\left(g_{j}\right)+u\left(c_{i}\right)
$$

where $H(\cdot)$ is the utility from public spending and $u(\cdot)$ is utility from private consumption. Utility from public spending depends upon the location of the individual $i$ through the function $f(i)$.

The utility function we use to test the effects of the introduction of income inequalities derives from our benchmark models Alesina and Spolaore (1997) and Etro (2006). In particular, the utility function used by Etro, given the introduction of income differences, becomes:

$$
U_{i j}=\frac{g_{j}^{1-\theta}}{1-\theta}\left[\lambda-a d\left(i, l_{g j}\right)\right]+y_{i}-\frac{t_{i}^{2}}{2}
$$


Utility from public spending $g$ is assumed to be isolelastic. $\theta \in(0,1)$ represents the elasticity of marginal utility of public expenditure (the lower it is, the more public and private consumption are substitutable).

The term in parenthesis $\left[\lambda-a d\left(i, l_{g j}\right)\right]$ concerns heterogeneity of preferences between individuals depending on their own distance from the point where public good is located: $\lambda>0$ represents the maximum utility from public good, $a \geq 4 \lambda$ reflects the costs of heterogeneity and $d\left(i, l_{g j}\right)=\left|i-l_{g j}\right|$ is the distance between the location of individual $i$ and the location of public good $g$ in jurisdiction $j$. Within our framework individuals' utility from public spending depends upon their own location in the geographical space. In particular, we need that utility of individuals decreases together with the distance from the point where public good is located, ceteris paribus.

We also assume that utility is linear in private consumption.

There are specific assumptions on the technology of production of public goods; in particular, we assume that the cost function of taxation is a quadratic one. Such formalization is the same as the one of Etro; it entails the presence of diminishing marginal returns in the production process of public goods with a distortion of taxes increasing and convex in the taxation level. ${ }^{5}$ It is useful because of the mathematical tractability of the First Order Conditions. Alesina and Spolaore do not need to make any assumption on the technology of production of public goods because their utility from the exogenous public spending is a given parameter and the cost of production and tax distortions is another unrelated and exogenous parameter.

Comparison between our utility function and the ones of Alesina and Spolaore (1997) and Etro (2006)

\begin{tabular}{|c|c|c|c|}
\hline & AS97 & E06 & this paper \\
\hline Utility from public spending & $g$ & $\frac{g_{j}^{1-\theta}}{1-\theta}$ & $\frac{g_{j}^{1-\theta}}{1-\theta}$ \\
\hline Heterogeneity of preferences & $1-a l_{i}$ & $\lambda-a l_{i}$ & $\lambda-a\left|i-l_{g j}\right|$ \\
\hline "Costs" of taxation/public good & $/$ & $-\frac{t_{j}^{2}}{2}$ & $-\frac{t_{i j}^{2}}{2}$ \\
\hline
\end{tabular}

\footnotetext{
${ }^{5}$ The recent empirical literature (Feldstein 1999, Goolsbee 2000, Gruber and Saez 2002) has shown that the standard way to model deadweight losses from taxation (Harberger 1964) significantly understimates DWL. In particular, the traditional view does not take into account that the constrained elasticity of labor income and the realtive price of ordinary consumption increase together with income. Our way to model DWL is a (rough) proxy for the framework proposed by Feldstein, where DWL are shown to be even ten times larger than in Harberger.
} 
Given that in our model individuals differ about location and income, the utility of a poor individual $i$ in country $j$ is given by:

$$
U_{i_{P} j}=\frac{g_{j}^{1-\theta}}{1-\theta}\left(\lambda-a d\left(i, l_{g j}\right)\right)+y_{j}-\frac{t_{j P}^{2}}{2}
$$

if $i \in P \subseteq[0,1]$.

On the other hand, the utility of a rich individual $i$ in country $j$ is given by:

$$
U_{i_{R} j}=\frac{g^{1-\theta}}{1-\theta}\left(\lambda-a d\left(i, l_{g j}\right)\right)+k y_{j}-\frac{t_{j R}^{2}}{2}
$$

if $i \in R \subseteq[0,1]$.

\subsection{Taxation scheme and budget constraint}

Each individual pays taxes and enjoys benefits from public good in the country where he lives.

Taxes are assumed to be proportional with respect to income, therefore the tax rate is given by $\tau_{j} \in(0,1)$ and the tax revenue from individual $i$ (in country $j$ ) is given by $t_{i}=\tau_{j} y_{i}$.

The budget constraint of our model derives from the assumptions on the distributions of population and incomes. Public spending equals tax revenue multiplied by country size $s_{j}$. Notice that $s_{j}$, given uniform distribution of individuals, represents not only the size of the country but also its population.

Under the assumption that taxes are proportional with respect to income, the budget constraint for country $j$ is given by:

$$
g_{j}=s_{j} \tau_{j}[\alpha y+(1-\alpha) k y]
$$

\section{Normative equilibrium (social planner solution)}

We derive the normative equilibrium through a two-stage process. In the first stage, an utilitarian social planner chooses the number of nations and the level of public spending within each country; in the second stage, he locates the public good within each jurisdiction.

In the first stage, the utilitarian social planner maximizes: 


$$
\begin{gathered}
W(g, s, t)=\sum_{j=1}^{N} \int_{s_{j}} U_{i j} d i \\
\text { s.t. } \quad g_{j}=s_{j} t_{j}
\end{gathered}
$$

Notice that the social planner knows the location of the individuals and also the distribution of incomes.

Our paper focus on symmetric partitions of the world, given the distribution of individuals and incomes. If countries are equal-sized, we have:

$$
s_{j}=s \quad \forall j \in(1, N)
$$

As a consequence, from now on subscript $j$ will be omitted.

In the second stage, the social planner chooses the location of the public good within each jurisdiction in order to minimize the "costs of distance" from public good. As we have already pointed out in Section 2.2, the distance of each individual from public good is given by:

$$
d\left(i, l_{g}\right)=\left|i-l_{g}\right|
$$

The total cost of distance from $g$ within each country is given by:

$$
L(i)=\int_{s} d\left(i, l_{g}\right) f(i) d i
$$

Under the assumption of uniform distribution, the previous integral reduces to:

$$
L(i)=\int_{s} d\left(i, l_{g}\right) d i
$$

And the utilitarian social planner locates public good solving:

$$
\min L(i)=\min \int_{s} d\left(i, l_{g}\right) d i
$$

It follows that public good is located in the middle of each jurisdiction.

As a consequence of the location of public good, the utilitarian social planner maximizes:

$$
\begin{aligned}
W(g, s, t)= & \alpha\left[\frac{g^{1-\theta}}{1-\theta}\left(\lambda-a \frac{s}{4}\right)+y-\frac{t_{P}^{2}}{2}\right]+ \\
& +(1-\alpha)\left[\frac{g^{1-\theta}}{1-\theta}\left(\lambda-a \frac{s}{4}\right)+k y-\frac{t_{R}^{2}}{2}\right]
\end{aligned}
$$


under the budget constraint $g=s t$. Notice that $s / 4$ is the median distance between the center of the country and country borders.

Rearranging the terms in the previous equation we obtain:

$$
W(g, s, t)=\frac{g^{1-\theta}}{1-\theta}\left(\lambda-a \frac{s}{4}\right)+[\alpha y+(1-\alpha) k y]-\left[\alpha \frac{t_{P}^{2}}{2}+(1-\alpha) \frac{t_{R}^{2}}{2}\right]
$$

The first term in square brackets equals average income; the second one equals the costs of taxation given the distribution of incomes.

Let's focus on the costs of taxation given income distribution. Given a proportional taxation scheme and the budget constraint $g=s t$ we derive:

$$
\alpha \frac{t_{P}^{2}}{2}+(1-\alpha) \frac{t_{R}^{2}}{2}=\frac{1}{2}\left(\frac{g}{s}\right)^{2} \frac{\alpha+(1-\alpha) k^{2}}{[\alpha+(1-\alpha) k]^{2}}
$$

In order to get the normative equilibrium, the utilitarian social planner maximizes with respect to size and public good provision the following equation:

$$
W(g, s)=\frac{g^{1-\theta}}{1-\theta}\left(\lambda-a \frac{s}{4}\right)+\bar{y}-\frac{1}{2}\left(\frac{g}{s}\right)^{2} \psi
$$

where:

$$
\psi:=\frac{\alpha+(1-\alpha) k^{2}}{[\alpha+(1-\alpha) k]^{2}}>1
$$

is a linear transformation of the Generalized Entropy Index with parameter equal to 2 .

Generalized Entropy Index, if the parameter equals 2, is given by:

$$
E_{2}=\frac{1}{2}\left[\int\left(\frac{y_{i}}{\bar{y}}\right)^{2} d F-1\right]
$$

Where $F$ represents income distribution function.

Given the distribution of incomes in our model, we have:

$$
E_{2}=\frac{1}{2}\left\{\alpha\left[\frac{y}{\alpha y+(1-\alpha) k y}\right]^{2}+(1-\alpha)\left[\frac{k y}{\alpha y+(1-\alpha) k y}\right]^{2}-1\right\}
$$

It reduces to:

$$
E_{2}=\frac{1}{2}\left\{\frac{\alpha+(1-\alpha) k^{2}}{[\alpha+(1-\alpha) k]^{2}}-1\right\}
$$


Equivalently, we have:

$$
\psi=2 E_{2}+1
$$

Generalized Entropy Index is a convenient measure of income inequality as it satisfies important properties. ${ }^{6}$

In our model, the index derives from the component of $W$ concerning the technology of production of public goods; de facto, it shows the variation in the average costs of taxation that follows the introduction of income inequalities. Given a proportional taxation scheme, the numerator approximates the average costs of taxation we observe, given income distribution, and the denominator approximates the costs of taxation we would have in case of uniform income. Notice that in case of uniform income the costs of taxation would be minimized.

\subsection{Derivation of the normative equilibrium}

Let us consider the First Order Condition ${ }^{7}$ of $(3)$ with respect to size: ${ }^{8}$

$$
\frac{\partial W}{\partial s}=-g^{1-\theta} \frac{a}{4(1-\theta)}+\frac{g^{2}}{s^{3}} \psi=0
$$

It follows that:

$$
s=g^{\frac{1+\theta}{3}}\left[\frac{4(1-\theta) \psi}{a}\right]^{\frac{1}{3}}
$$

The size of nation chosen by the social planner is an increasing and convex function of the provision of public goods. It increases together with the provision of public good in order to properly exploit the economies of scale. On the other hand, there is an inverse relationship between the costs of heterogeneity and size.

Merging (5) and the budget constraint (2), we obtain:

$$
t=s^{\frac{2-\theta}{1+\theta}}\left[\frac{a}{4(1-\theta) \psi}\right]^{\frac{1}{1+\theta}}=\Psi(s)
$$

\footnotetext{
${ }^{6}$ First of all, Generalized Entropy Index satisfies the Strong Principle of Transfers, so that any transfer of income from a rich person to a poor one reduces measured inequality proportionally to the distance in terms of income between the two individuals. Furthermore, the Index is income scale independent, so the measured inequality of the slices of the cake do not depend on the size of the cake. It is also population independent, so the measured inequality does not depend on the number of individuals we consider.

${ }^{7}$ Second Order Conditions are satisfied. See the Appendix for details.

${ }^{8}$ Notice that in the mathematical derivation of the equilibrium we do not take into account the constraint $1 / s \in \mathbb{N}_{+}$where $\mathbb{N}_{+}$is the set of positive natural numbers, but such constraint is taken into account in the results of the model.
} 
$(5 A)$ suggests a positive correlation between country size and average public spending per capita. Such correlation contrasts the empirical results of the paper by Alesina and Wacziarg (1998), who have showed a robust negative correlation between the two variables. (5A) also shows an inverse relationship between tax rate and income inequality; both in theoretical and empirical analyses there are controversies on this issue. Beyond this point, the economic intuition suggests that if income inequality increases it would be more difficult to target the public good on the preferences of citizens.

The First Order Condition ${ }^{7}$ of (3) with respect to public good provision gives us:

$$
g=s^{\frac{2}{1+\theta}}\left(\lambda-a \frac{s}{4}\right)^{\frac{1}{1+\theta}}\left(\frac{1}{\psi}\right)^{\frac{1}{1+\theta}}
$$

The public good provision chosen by the social planner is an inverted U function of the size of nations. Merging (6) and the budget constraint (2), we obtain:

$$
t=s^{\frac{1-\theta}{1+\theta}}\left(\lambda-a \frac{s}{4}\right)^{\frac{1}{1+\theta}}\left(\frac{1}{\psi}\right)^{\frac{1}{1+\theta}}=\Phi(s)
$$

(6A) suggests that there is a trade off between heterogeneity costs and benefits from scale economies in the provision of public goods. Both these effects are increasing in the size of nations, therefore the net benefits from public good provision are maximized at an "intermediate" size. The effect of income inequality is the same already discussed for $(5 A)$.

Given $N^{*}=1 / s^{*}$, let us derive the results in terms of $N \in \mathbb{R}_{+}$where $\mathbb{R}_{+}$is the set of positive real numbers solving:

$$
\Psi(s)=\Phi(s)
$$

It follows that:

$$
N^{*}=\frac{a(2-\theta)}{4 \lambda(1-\theta)}
$$

And merging (6) and (7), we obtain:

$$
g\left(N^{*}\right)=\left\{\left(\frac{\lambda}{2-\theta}\right)^{3}\left[\frac{4(1-\theta)}{a}\right]^{2} \frac{1}{\psi}\right\}^{\frac{1}{1+\theta}}
$$

Notice that (7) and (8) are results of the model if and only if $N^{*} \in \mathbb{N}_{+}$, where $\mathbb{N}_{+}$is the set of positive natural numbers.

If $N^{*} \notin \mathbb{N}_{+}$, we have to take into account that the number of nations must belong to the set of positive natural number; that is, the constraint $N \in \mathbb{N}_{+}$applies. 
Let us define:

$\left\lfloor\frac{a(2-\theta)}{4 \lambda(1-\theta)}\right\rfloor=N_{-}$where $\lfloor\cdot\rfloor$ is the floor of $\cdot ;$ that is, the largest $\mathbb{N}_{+} \leq \cdot$

$\left\lceil\frac{a(2-\theta)}{4 \lambda(1-\theta)}\right\rceil=N_{+}$where $\lceil\cdot\rceil$ is the ceiling of $\cdot ;$ that is, the smallest $\mathbb{N}_{+} \geq \cdot$ $\left[\frac{1}{\left(N_{-}\right)^{2} \psi}\left(\lambda-\frac{a}{4\left(N_{-}\right)}\right)\right]^{\frac{1}{1+\theta}}=g\left(N_{-}\right)$; that is, the level of public spending within each jurisdiction associated with $N_{-}$.

$\left[\frac{1}{\left(N_{+}\right)^{2} \psi}\left(\lambda-\frac{a}{4\left(N_{+}\right)}\right)\right]^{\frac{1}{1+\theta}}=g\left(N_{+}\right)$; that is, the level of public spending within each jurisdiction associated with $N_{+}$.

Given that the Second Order Conditions are satisfied, ${ }^{9} N^{*}$ maximizes $W$; that is, $N^{*}$ is strictly preferred to both $N_{-}$and $N_{+}$in terms of welfare, but it can be implemented only if $N^{*} \in \mathbb{N}_{+}$.

If $N^{*} \notin \mathbb{N}_{+}$, the social planner chooses between $N_{-}$and $N_{+}$on the basis of the condition:

$W\left(\left(N_{-}\right), g\left(N_{-}\right)\right) \gtreqless W\left(\left(N_{+}\right), g\left(N_{+}\right)\right)$

The previous condition reduces to:

$$
\left(\frac{1}{N_{-}}\right)^{1-\theta}\left(\lambda-\frac{a}{4 N_{-}}\right) \gtreqless\left(\frac{1}{N_{+}}\right)^{1-\theta}\left(\lambda-\frac{a}{4 N_{+}}\right)
$$

PROPOSITION 1 The number of nations and the level of public spending within each country chosen by the social planner are given by:

$$
\begin{array}{ll}
N^{*}, g\left(N^{*}\right) & \text { if } \quad N^{*} \in \mathbb{N}_{+} \\
N_{-}, g\left(N_{-}\right) & \text {if } N^{*} \notin \mathbb{N}_{+} \text {and } W\left(\left(N_{-}\right), g\left(N_{-}\right)\right) \geq W\left(\left(N_{+}\right), g\left(N_{+}\right)\right) \\
N_{+}, g\left(N_{+}\right) & \text {if } N^{*} \notin \mathbb{N}_{+} \text {and } W\left(\left(N_{-}\right), g\left(N_{-}\right)\right) \leq W\left(\left(N_{+}\right), g\left(N_{+}\right)\right)
\end{array}
$$

\footnotetext{
${ }^{9}$ See the Appendix for details.
} 
Both size and public spending increase together with absolute utility from public good: the higher is the value of $\lambda$, the higher is the utility from $g$, ceteris paribus. Furthermore, optimal size and optimal public good provision decrease as the costs of heterogeneity increase.

Our analysis also shows that, if income inequality increases, it would be optimal to lower the tax rate. The economic intuition suggests that if income inequality increases, individuals prefer less public good because its "average distance" from the preferences of individuals increases together with the measured income inequality. Our results are in this line but the inverse relationship between income inequality and public spending depends upon the presence of a distortionary (proportional) taxation scheme

\subsection{Theoretical analysis and empirical analysis}

After the introduction of income inequalities through a two-spike distribution, we show that there is an inverse relationship between income inequality and public spending.

Such inverse relationship contrasts the results obtained by Persson and Tabellini (2000): in their theoretical model, optimal public good provision under proportional taxation scheme rises as median income drops relative to average income. ${ }^{10}$ There are important differences between our model and the one of Persson and Tabellini. We derive the normative solution through the vision of an utilitarian social planner that maximizes the utility of the median individual in terms of geographical location; Persson and Tabellini maximize the utility of the individual with median income through a voting model where Median Voter Theorem holds. Beyond this point, both in Persson and Tabellini and in our model an increase in income skewness and/or income inequality leads to a smaller redistribution in equilibrium.

On the other hand, the theoretical work by Lind (2007) confirms the inverse relationship between inequality and public spending. There are fundamental differences between our work and the one of Lind in terms of assumptions on income distribution: we consider a "spiked" distribution with perfect homogeneity within each group; Lind considers a distribution of incomes where within groups heterogeneity exists. The result of his model depends upon the differences in densities within different groups; he shows that a mean-preserving increase in between-groups inequality decreases the

\footnotetext{
${ }^{10}$ Persson and Tabellini consider income skewness (mean/median ratio); we consider income inequality (Generalized Entropy Index). Given our two-spike distributions, an increase in income differential between rich and poor increases both income skewness and income inequality.
} 
politically chosen tax rate. Given different assumptions on income distribution, we observe similar results within different frameworks.

The results of empirical analyses on the effects of income inequality on public expenditure seems to confirm our results. In the econometric analysis by Alesina, Baqir and Easterly (1999), ${ }^{11}$ income inequality ${ }^{12}$ has negative effect on per capita education spending. Also the work by Lindert $(1996)^{13}$ shows that an increase in income inequality lowers total public expenditure as share of GDP.

\section{Positive equilibrium (equilibrium geography)}

In this section, we check how different preferences on country size affects the equilibrium geography of the model ${ }^{14}$, given the endogenous amount of public good depending upon the size of the jurisdiction. ${ }^{15}$ We assume that also in the derivation of equilibrium geography the public good is located in the middle of each jurisdiction. ${ }^{16}$

Following the framework proposed by Alesina and Spolaore, we define rules for border redrawing in order to study the equilibrium number of countries. Under Rule i, we require that each individual can choose whether to live in its country or in autarchy; that is, without public good provision and taxation. Under Rule ii, we require that nobody living at the border between two countries can be forced to belong to a country if he prefers to join the other one.

\footnotetext{
${ }^{11}$ This paper is an econometric analysis of public spending at local level within the U.S..

${ }^{12}$ Alesina, Baqir and Easterly measure income inequality through mean/median ratio; de facto, they consider income skewness as a proxy for income inequality.

${ }^{13}$ This paper is an econometric analysis of the determinants of public spending in 19 OECD countries from 1960 to 1992.

${ }^{14}$ In our model we follow the definition of "equilibrium" we find in Alesina and Spolaore (1997) in order to get "stable" results. In future works, it would be interesting to test the validity of our results in case of a more general notion of stability that considers Nash stable partitions and core partitions. In this respect, it could be possible to follow, for example, the framework proposed by Bogomolnaia, Le Breton, Savvateev and Weber (2008).

${ }^{15}$ The amount of public good within each jursdiction is given by (6):

$g=s^{\frac{2}{1+\theta}}\left(\lambda-a \frac{s}{4}\right)^{\frac{1}{1+\theta}}\left(\frac{1}{\psi}\right)^{\frac{1}{1+\theta}}$

${ }^{16}$ Suppose that (i) the social planner minimizes the costs of distance from each place where public good is located or (ii) within each country the location of public good is decided by majority rule. In both cases public good is located in the middle of each jurisdiction. Alesina and Spolaore (1997), for example, use method (i) in the derivation of the normative equilibrium and method (ii) in the derivation of the positive equilibrium.
} 
Rules for border redrawing can be summarized as follows:

Rule i Each individual can choose between status quo and autarchy.

Rule ii Each individual at the border between two countries can choose which country to join.

A configuration of $N$ countries is:

An i/ii-equilibrium if the borders of the $N$ nations are not subject to change under Rule i and Rule ii.

$\mathrm{i} /$ ii-stable if it is an i/ii-equilibrium and it is stable under Rule i and Rule ii.

Our notion of i/ii-stability implies that if an i/ii-equilibrium is subject to a "small" perturbation, the system returns to the original position. A "small" perturbation occurs when some individuals live in autarchy and/or some individuals change their citizenship.

Formally, a configuration of $N$ countries is i/ii-stable if and only if the following conditions hold:

$$
\begin{aligned}
V_{P}(s / 2) & \geq y \\
\partial V_{P}(s / 2) / \partial s & \leq 0 \\
V_{R}(s / 2) & \geq k y \\
\partial V_{R}(s / 2) / \partial s & \leq 0
\end{aligned}
$$

where $V_{i}(s / 2)$ is the expected utility of the individual $i$ living at country borders, $(i P)$ is Rule i for poor individuals, $(i i P)$ is Rule ii for poor individuals, $(i R)$ is Rule i for rich individuals, $(i i R)$ is Rule ii for rich individuals,.

Under Rule i we require that for each individual the loss of utility deriving from taxation cannot be superior to the increase in utility deriving from public good provision. ${ }^{17}$

Under Rule ii we require that each individual living at the border between two countries of different size will prefer to join the smallest one. ${ }^{18}$

\footnotetext{
${ }^{17}$ Alesina and Spolaore (1997) do not need to explicitly consider Rule i given their assumptions on the parameters of the utility function. Rule $\mathrm{i}$ is equivalent to Condition 1 in Etro (2006). Notice that if Rule i holds for citizens living at country border a fortiori it holds for any other individual, given that in our model the utility of individuals decreases together with the distance from the middle of each country where $g$ is located, ceteris paribus.

${ }^{18}$ Let us recall once again that in our model the utility of individuals decreases together
} 


\subsection{Derivation of the positive equilibrium}

In order to check i/ii-stability, we have to consider the expected utilities of poor and rich individuals living at country borders given (6):

$$
\begin{aligned}
V_{P}(s / 2)= & {\left[\frac{s^{2}}{\psi}\left(\lambda-a \frac{s}{4}\right)\right]^{\frac{1-\theta}{1+\theta}} } \\
& {\left[\frac{\lambda-a \frac{s}{2}}{1-\theta}-\frac{1}{2\left[\alpha+(1-\alpha) k^{2}\right]}\left(\lambda-a \frac{s}{4}\right)\right]+y } \\
V_{R}(s / 2)= & {\left[\frac{s^{2}}{\psi}\left(\lambda-a \frac{s}{4}\right)\right]^{\frac{1-\theta}{1+\theta}} } \\
& {\left[\frac{\lambda-a \frac{s}{2}}{1-\theta}-\frac{k^{2}}{2\left[\alpha+(1-\alpha) k^{2}\right]}\left(\lambda-a \frac{s}{4}\right)\right]+k y }
\end{aligned}
$$

With respect to poor individuals, we have:

$$
\begin{gathered}
\frac{[-4 \lambda(2 \phi+\theta-1)+a s(4 \phi+\theta-1)]\left[\frac{s^{2}}{\psi}\left(\lambda-a \frac{s}{4}\right)\right]^{\frac{1-\theta}{1+\theta}}}{8 \phi(\theta-1)} \geq 0 \quad \text { (iP) } \\
\frac{\left\{16 \lambda^{2}(\theta-1)(2 \phi+\theta-1)+a^{2} s^{2}(\theta-2)(4 \phi+\theta-1)-4 a s \lambda[3-9 \phi+\theta(5 \phi+2 \theta-5)]\right\} \psi\left[\frac{s^{2}}{\psi}\left(\lambda-a \frac{s}{4}\right)\right]^{\frac{2}{1+\theta}}}{s^{3} \phi\left(\theta^{2}-1\right)(a s-4 \lambda)^{2}} \leq 0
\end{gathered}
$$

where:

$$
\phi=\alpha+(1-\alpha) k^{2}
$$

As a consequence, a configuration of $N$ countries is i/ii-stable for poor individuals only if it belongs to the interval:

$$
\tilde{s}_{P} \in\left[\frac{2 \lambda}{a} \frac{3-9 \phi+\theta(5 \phi+2 \theta-5)+\sqrt{(\theta-1)^{2}-2 \phi\left[3+\theta^{2}(2 \theta-5)\right]-\phi^{2}[\theta(7 \theta-6)-17]}}{(\theta-2)(4 \phi+\theta-1)}, \frac{4 \lambda}{a} \frac{2 \phi+\theta-1}{4 \phi+\theta-1}\right]
$$

Let us express the interval in $(10 P)$ as:

with the distance from $g$, ceteris paribus. Rule ii is equivalent to Rule A in Alesina and Spolaore (1997) and Condition 2 in Etro (2006). 


$$
I_{P}(\lambda, \alpha, k, \theta)
$$

With respect to rich individuals, we have:

$$
\begin{gathered}
\frac{[-4 \lambda(2 \beta+\theta-1)+a s(4 \beta+\theta-1)]\left[\frac{s^{2}}{\psi}\left(\lambda-a \frac{s}{4}\right)\right]^{\frac{1-\theta}{1+\theta}}}{8 \beta(\theta-1)} \geq 0 \quad \text { (iR) } \\
\frac{\left\{16 \lambda^{2}(\theta-1)(2 \beta+\theta-1)+a^{2} s^{2}(\theta-2)(4 \beta+\theta-1)-4 a s \lambda[3-9 \beta+\theta(5 \beta+2 \theta-5)]\right\} \psi\left[\frac{s^{2}}{\psi}\left(\lambda-a \frac{s}{4}\right)\right]^{\frac{2}{1+\theta}}}{s^{3} \beta\left(\theta^{2}-1\right)(a s-4 \lambda)^{2}} \leq 0
\end{gathered}
$$

where:

$$
\beta=\frac{\alpha+(1-\alpha) k^{2}}{k^{2}}=\frac{\phi}{k^{2}}
$$

As a consequence, a configuration of $N$ countries is i/ii-stable for rich individuals only if it belongs to the interval:

$$
\tilde{s}_{R} \in\left[\frac{2 \lambda}{a} \frac{3-9 \beta+\theta(5 \beta+2 \theta-5)+\sqrt{(\theta-1)^{2}-2 \beta\left[3+\theta^{2}(2 \theta-5)\right]-\beta^{2}[\theta(7 \theta-6)-17]}}{(\theta-2)(4 \beta+\theta-1)}, \frac{4 \lambda}{a} \frac{2 \beta+\theta-1}{4 \beta+\theta-1}\right]
$$

Let us express the interval in $(10 R)$ as:

$$
I_{R}(\lambda, \alpha, k, \theta)
$$

In particular, we have:

The stable interval for poor individuals $I_{P}$ is always non-empty.

The stable interval for rich individuals $I_{R}$ can be non-empty or empty, depending upon income distribution (and substitutability between public and private goods).

i/ii-stable equilibria exist only if $I_{P} \cap I_{R}$ is non-empty. Our analysis shows that $I_{P} \cap I_{R}$ can be non-empty only if:

$$
2 \frac{\alpha+(1-\alpha) k^{2}}{k^{2}}+\theta>1
$$


holds $;^{19}$ that is, $(N C)$ is a necessary condition for the existence of $\mathrm{i} /$ ii stable equilibria.

Assuming that $(N C)$ holds, we have $\min I_{P}>\min I_{R}$ and $\max I_{P}>$ $\max I_{R}$, therefore $I_{P} \cap I_{R}$ is non-empty only if:

$$
\max I_{R}(\lambda, \alpha, k, \theta)>\min I_{P}(\lambda, \alpha, k, \theta)
$$

or, equivalently:

$$
\frac{2(2 \beta+\theta-1)}{4 \beta+\theta-1}-\frac{3-9 \phi+\theta(5 \phi+2 \theta-5)+\sqrt{(\theta-1)^{2}-2 \phi\left[3+\theta^{2}(2 \theta-5)\right]-\phi^{2}[\theta(7 \theta-6)-17]}}{(\theta-2)(4 \phi+\theta-1)}>0
$$

\section{PROPOSITION 2}

If $2 \frac{\alpha+(1-\alpha) k^{2}}{k^{2}}+\theta \leq 1$, no i/ii-stable equilibria exist.

If $2 \frac{\alpha+(1-\alpha) k^{2}}{k^{2}}+\theta>1$ the existence of $\mathbf{i} / \mathbf{i i}$-stable equilibria depends upon the values of $\alpha, k, \theta$.

Notice that even if $(N C)$ holds, given $\alpha$ and $\theta$, no stable equilibria exist if $k$ is "sufficiently high".

For poor individuals i/ii-stable size increases as income differential increases. If income differential and the size of country increase, poor individuals would have to pay a smaller share of the tax burden in order to get the same per-capita provision of public good, ceteris paribus. The effect of an increase in the percentage of poor is opposite; poor individuals would have to pay a larger share of the tax burden in order to get the same per-capita provision of public good, ceteris paribus; as a consequence, they would prefer less public good provision and less distance from the government in a smaller country.

For rich individuals, the effects of an increase in income differential or in the percentage of poor increase are the same. In both cases, with taxes proportional to income, they pay a larger share of the tax burden, ceteris paribus. If rich individuals pay (relatively) more taxes, they would prefer a smaller country to join more benefits from the public goods they have paid for. As we have already pointed out before, autarchy is preferred by rich

\footnotetext{
${ }^{19} I_{R}$ is non empty if $2 \frac{\alpha+(1-\alpha) k^{2}}{k^{2}}+\theta>1$ or $4 \frac{\alpha+(1-\alpha) k^{2}}{k^{2}}+\theta<1$. If $4 \frac{\alpha+(1-\alpha) k^{2}}{k^{2}}+\theta<1$, we have $I_{P} \cap I_{R}=\emptyset$.
} 
individuals and no i/ii stable solution in the sense of Alesina and Spolaore exist if income differential is "sufficiently high".

Our paper shows that the results of Alesina and Spolaore and Etro for equilibrium geography seem to be not robust to the introduction of income inequalities in the sense that a "sufficiently high" income inequality implies non existence of positive equilibria in the sense of Alesina and Spolaore.

\subsection{Income inequalities and instability}

There are cases where an equilibrium geography in the sense of Alesina and Spolaore does not exist. The higher is income inequality, the more the preferences of individuals on size diverge; if income differential is "sufficiently high" or $(N C)$ does not hold, an i/ii-stable equilibrium does not exist. A strong link between inequality and instability emerges. ${ }^{20}$

Let us compare such result with the ones of Haimanko, Le Breton and Weber (2005), who develop a model where heterogeneity is given by the distribution of individuals in the geographical space and incomes are not considered. They study how governments can prevent secession threats through redistribution schemes, given the distribution of individuals. In both the models geographical and preference dimensions coincide but we focus on income differences within an uniformly distributed population. In spite of these differences, their degree of polarization in the geographical distribution of individuals can be considered as a counterpart of the Generalized Entropy Index $\psi$. Following this argument, a comparison of the results is possible. Haimanko, Le Breton and Weber show that in case of an highly polarized population efficiency does not imply stability without redistribution; that is, the efficient size is greater than the stable one. Within our framework redistribution schemes cannot be implemented ${ }^{21}$ and we show that in case of high income inequality no equilibrium geography is possible.

There are also empirical works on the link between income distribution and political instability. The econometric analysis by Alesina and Perotti

\footnotetext{
${ }^{20}$ Notice that in our model we consider also the effect of the substitutability between public and private goods on i/ii-stability. If $(N C)$ holds, the higher the substitutability between public and private goods (the lower $\theta$ ), the more the model is expected to be i/ii-unstable, given income distribution.

${ }^{21}$ Alesina and Spolaore (1997) proved that in their model a redistribution scheme cannot be implemented (page 1054-1055). Given uniformly distributed population and pairwise majority voting on redistribution schemes, for every country size $s_{j}$ there will always be a majority against redistribution schemes formed by individuals living at a distance from the middle of each jurisdiction (where public good is located) that is not superior to the median one; that is, a majority formed by each $i$ living in $j$ such that $d\left(i_{j}, g_{j}\right) \leq s_{j} / 4$.
} 
(1996) on 71 countries between 1960 and 1985 shows that political stability is enhanced by the presence of a wealthy middle class. Alesina and Perotti focuses on causal relationship, but, as noted by Acemoglu and Robinson (2006), in many cases the existing literature on this topic is contradictory and focuses on correlations instead of causal relationships.

\section{Conclusion}

In this paper we have discussed the effects of the introduction of income inequality in well-known models on geopolitical organizations.

We find that in the normative solution there is in an inverse relationship between income inequality and public spending. Our main finding on equilibrium geography concerns the existence of equilibria in the sense of Alesina and Spolaore. In our benchmark models such equilibria exist, but after the introduction of income heterogeneity we show that there are cases where they do not exist depending upon income inequality; in particular, there is a direct relationship between income differential and instability.

The model of Alesina and Spolaore modified à la Etro seems not to be robust to the introduction of income heterogeneity. This result should not be interpreted as a negative one. Let us focus, for example, on the comparison between Haimanko, Le Breton and Weber (2005) and our paper: given the different assumptions of the models, our non-existence of equilibria in the sense of Alesina and Spolaore is the counterpart of their need for redistribution schemes in order to prevent secessions. In other words, an important result in the theoretical literature is confirmed within our multidimensional framework.

In 1997 Alesina and Spolaore highlighted five possible hints for future researches. Some of their "questions left open" are still open nowadays. In particular, it would be interesting to relax some of the assumptions on the distribution of individuals. Another interesting extension of the original model could concerns the mobility of individuals, so that Alesina and Spolaore (1997) could meet the framework proposed by Tiebout (1956).

Finally, another interesting issue to explore would concerns the discussion of more general notion of equilibrium, following, for example, Bogomolnaia, Le Breton, Savvateev and Weber (2008). 


\section{Appendix: Second Order Conditions of (3)}

The Hessian matrix of $W(s, g)$ :

$$
D^{2} W\left(s^{*}, g^{*}\right)=\left[\begin{array}{ll}
\frac{\partial^{2} W}{\partial s \partial s} & \frac{\partial^{2} W}{\partial g \partial s} \\
\frac{\partial^{2} W}{\partial s \partial g} & \frac{\partial^{2} W}{\partial g \partial g}
\end{array}\right]
$$

$\left(s^{*}, g^{*}\right)$ are strict local maximizers of $W(s, g)$ if and only if:

$$
\operatorname{det} D^{2} W\left(s^{*}, g^{*}\right)=\frac{\partial^{2} W}{\partial s \partial s} \frac{\partial^{2} W}{\partial g \partial g}-\left(\frac{\partial^{2} W}{\partial s \partial g}\right)^{2}>0
$$

Given the First Order Condition of (3) with respect to size:

$$
\frac{\partial W}{\partial s}=-g^{1-\theta} \frac{a}{4(1-\theta)}+\frac{g^{2}}{s^{3}} \psi=0
$$

It follows that:

$$
\frac{\partial^{2} W}{\partial s \partial s}=-3 \frac{g^{2}}{s^{4}} \psi<0
$$

Given the First Order Condition of (3) with respect to public good provision:

$$
\frac{\partial W}{\partial g}=g^{-\theta}\left(\lambda-a \frac{s}{4}\right)-\frac{g}{s^{2}} \psi=0
$$

It follows that:

$$
\frac{\partial^{2} W}{\partial g \partial g}=-\theta g^{-(1+\theta)}\left(\lambda-a \frac{s}{4}\right)-\frac{1}{s^{2}} \psi<0
$$

Furthermore, we have:

$$
\frac{\partial^{2} W}{\partial s \partial g}=\frac{\partial^{2} W}{\partial g \partial s}=-\frac{a g^{-\theta}}{4}+\frac{2 g}{s^{3}} \psi
$$

$\left(s^{*}, g^{*}\right)$ are strict local maximizers of $W(s, g)$ as long as:

$$
\operatorname{det} D^{2} W\left(s^{*}, g^{*}\right)=\frac{g^{2}}{s^{6}}(2-\theta)(1+\theta) \psi^{2}>0
$$

Second order conditions are satisfied. 


\section{References}

Acemoglu, D., Robinson J. A. (2006), "Economic Origins of Dictatorship and Democracy", Cambridge University Press.

Alesina, A., Perotti, R. (1996), "Income Distribution, Political Instability, and Investment", European Economic Review, vol.40, 1203-1228.

Alesina, A., Spolaore, E. (1997), "On the Number and the Size of Nations", Quarterly Journal of Economics, vol.CXII, 1027-1056.

Alesina, A., Wacziarg, R. (1998), "Openness, Country Size and Government", Journal of Public Economics, vol.69, 305-321.

Alesina, A., Baqir, R., Easterly, W. (1999), "Public Goods and Ethnic divisions" , Quarterly Journal of Economics, vol.CXIV, 1243-1284.

Bogomolnaia, A., Le Breton, M., Savvateev, A., Weber, S. (2008), "Stability of Jurisdiction Structures under the Equal Share and Median Rules", Economic Theory, vol.34, 525-543.

Bolton, P., Roland, G. (1997), "The Breakup of Nations: a Political Economy Analysis", Quarterly Journal of Economics, vol.CXII, 1057-1090.

Buchanan, J. M., Faith, R. L. (1987), "Secession and the Limit of Taxation: Toward a Theory of Internal Exit", American Economic Review, vol.77, 1023-1031.

Esteban, J. M., Ray, D. (1994) "On the Measurement of Polarization", Econometrica, vol.62, 819-851.

Etro, F. (2006), "Political Geography", Public Choice, vol.127, 329-351.

Feldstein, M. (1999), "Tax Avoidance and the Deadweight Loss of the Income Tax", Review of Economics and Statistics, vol.81, 674-680.

Friedman D. (1977), "A Theory of the Size and Shape of Nations", Journal of Political Economy, vol.85, 59-77.

Goldsbee, A. (2000), "What Happens When You Tax the Rich? Evidence from Executive Compensation", Journal of Political Economy, vol.108, 352-378.

Gruber, J., Saez, E. (2002), "The Elasticity of Taxable Income: Evidence and Implications", Journal of Public Economics, vol.102, 1-32. 
Haimanko, O., Le Breton, M., Weber, S. (2005), "Transfers in a Polarized Country: Bridging the Gap Between Efficiency and Stability", Journal of Public Economics, vol.89, 1277-1303.

Harberger, A.C.,(1964), "Taxation, Resource Allocation, and Welfare" in Due, J. (ed.) "The Role of Direct and Indirect Taxes in the Federal Revenue System", Princeton University Press.

Lind, J.T. (2007), "Fractionalization and the Size of Government", Journal of Public Economics, vol.91, 51-76.

Lindert, P. (1996), "What Limits Social Spending?", Explorations in Economic History, vol.31, 1-36.

Persson, T., Tabellini, G. (2000), "Political Economics: Explaining Economic Policy", Massachusetts Institute of Technology Press.

Perroni, C., Scharf, K. A. (2001), "Tiebout with Politics: Capital Tax Competition and Constitutional Choices", Review of Economic Studies, vol.68, 133-154.

Tiebout, C. (1956), "A Pure Theory of Local Expenditures", Journal of Political Economy, vol.64, 416-426. 